\title{
Lingua portuguesa em Angola: breve discussão sobre a situação de seu ensino na Provincia do Namibe
}

\author{
Portuguese language in Angola: brief discussion on the situation \\ of its teaching in the Province of Namibe
}

Sabrina Rodrigues Garcia Balsalobre ${ }^{1}$

Elias Flores Kanusse ${ }^{2}$

Resumo: Esse estudo centra-se na realidade do ensino em Angola, especificamente na provincia do Namibe, haja vista que alunos frequentam a escola, mas sentem que não sabem falar português, muito embora seja a língua efetivamente materna da maioria dos alunos. A fim de realizar esse estudo, partimos da hipótese de que a norma linguística que fundamenta os livros didáticas angolanos é a portuguesa, ou seja, a variedade europeia do idioma. Nesse sentido, o português angolano não é considerado na elaboração dos livros didáticos e, por isso, os alunos angolanos têm sua autoestima prejudicada pela forma como o ensino é conduzido. Com esse intuito, esse trabalho enquadra-se teoricamente na Sociolinguística, mais especificamente na Sociolinguística Educacional e conta com três perspectivas metodológicas que são: 1) compreensão teórica da sociolinguística, através dos textos teóricos; 2) análise dos livros didáticos da

\footnotetext{
${ }^{1}$ Docente no curso de Letras da UNILAB - Campus dos Malês, na área de metodologia de ensino de língua portuguesa e estágio supervisionado. Pós-doutora na Área de Linguística Histórica (2017) e Doutora em Linguística e Língua Portuguesa (2015) pela Universidade Estadual Paulista Júlio de Mesquita Filho - instituição em que também defendeu seu mestrado (2009) e cursou a graduação (2006). Participa do Grupo de Estudos e Pesquisas Interdisciplinares em linguagem e Sociedade - GEPILIS (UNILAB/CNPQ)
}

2 Mestrando em Linguagem e Cultura pela UFBA. Possui graduação em Letras - Língua Portuguesa pela UNILAB.

Interfaces da Educ., Paranaíba, v.11, n.32, p. 606 - 631, 2020 
$7^{\mathrm{a}}$ a $12^{\mathrm{a}}$ classe; e 3) entrevista com alunos do Namibe, para compreender como é ensinado a eles a Língua Portuguesa. Em suma, observou-se que os alunos namibenses não falam tal como se aprende nas escolas. Isso mostra a necessidade de se aprofundar estudos sociolinguísticos sobre essa variedade e sobre as interferências que as línguas nacionais têm no português falado no Namibe.

Palavras-chave: variedade angolana da língua portuguesa. Sociolinguística Educacional. ensino de língua portuguesa. análise de livro didático.

Abstract: This study focuses on the reality of teaching in Angola, specifically in the province of Namibe, given that students attend school, but feel that they do not know how to speak Portuguese, even though it is the mother language of most students. In order to carry out this study, we started from the hypothesis that the linguistic standard that underlies Angolan textbooks is Portuguese, that is, the European variety of the language. In this sense, Angolan Portuguese is not considered in the preparation of textbooks and, for this reason, Angolan students have their self-esteem impaired by the way teaching is conducted. To that end, this work is theoretically framed in Sociolinguistics, more specifically in Educational Sociolinguistics and has three methodological perspectives which are: 1) theoretical understanding of sociolinguistics, through theoretical texts; 2) analysis of textbooks from 7 th to 12th grade; and 3) interview with students from Namibe, to understand how they are taught the Portuguese language. In short, it was observed that Namibian students do not speak as they learn in schools. This shows the need to deepen sociolinguistic studies on this variety and on the interferences that national languages have in Portuguese spoken in Namibe. 
Keywords: Angolan variety of the Portuguese language. Educational Sociolinguistics. Portuguese language teaching. textbook analysis.

\section{Introdução}

Esse artigo se propõe a analisar o ensino de Língua Portuguesa em Angola. Acerca disso, nossa grande preocupação recai sobre a realidade do ensino na provincia do Namibe, haja vista que alunos frequentam a escola, mas sentem que não sabem falar português, ainda que seja a língua efetivamente materna da maioria dos alunos. Em primeiro lugar, nesse trabalho, começamos por apresentar a provincia do Namibe, uma vez que, muito embora seja uma provincia angolana, trata-se de um local desconhecido, até mesmo, pelos angolanos. Em seguida, estabelecemos uma discussão sobre os alicerces teóricos e metodológicos que sustentam esse estudo para, posteriormente, passarmos a uma breve discussão dos resultados obtidos por meio da análise dos livros didáticos dedicados ao ensino de lingua portuguesa e de entrevistas realizadas com estudantes namibenses de ensino médio ${ }^{1}$.

Namibe é uma província de Angola (cf. mapa 01), localizada na região sul do país. Trata-se de uma região que conta com uma superficie de 57.091 $\mathrm{km}^{2}$, limitada a norte pela província de Benguela, a leste pela província da Huíla, a oeste pelo Oceano Atlântico e a sul pelo rio Cunene e pela República da Namíbia (cf. mapa 02). A província do Namibe tem atualmente cinco municípios, a saber: Bibala, Kamucuio, Moçâmedes, Tômbwa e Virei. A capital da provincia é a cidade do Namibe, que atualmente é chamada de Moçâmedes (cf. mapa 03).

1 Conforme será melhor detalhado adiante, os alunos entrevistados do ensino médio estudam na Escola de Formação de Professores Patrice Lumumba, localizada no município de Moçâmedes.

Interfaces da Educ., Paranaíba, v.11, n.32, p. 606 - 631, 2020 
Mapa 01: Mapa da África com destaque para Angola

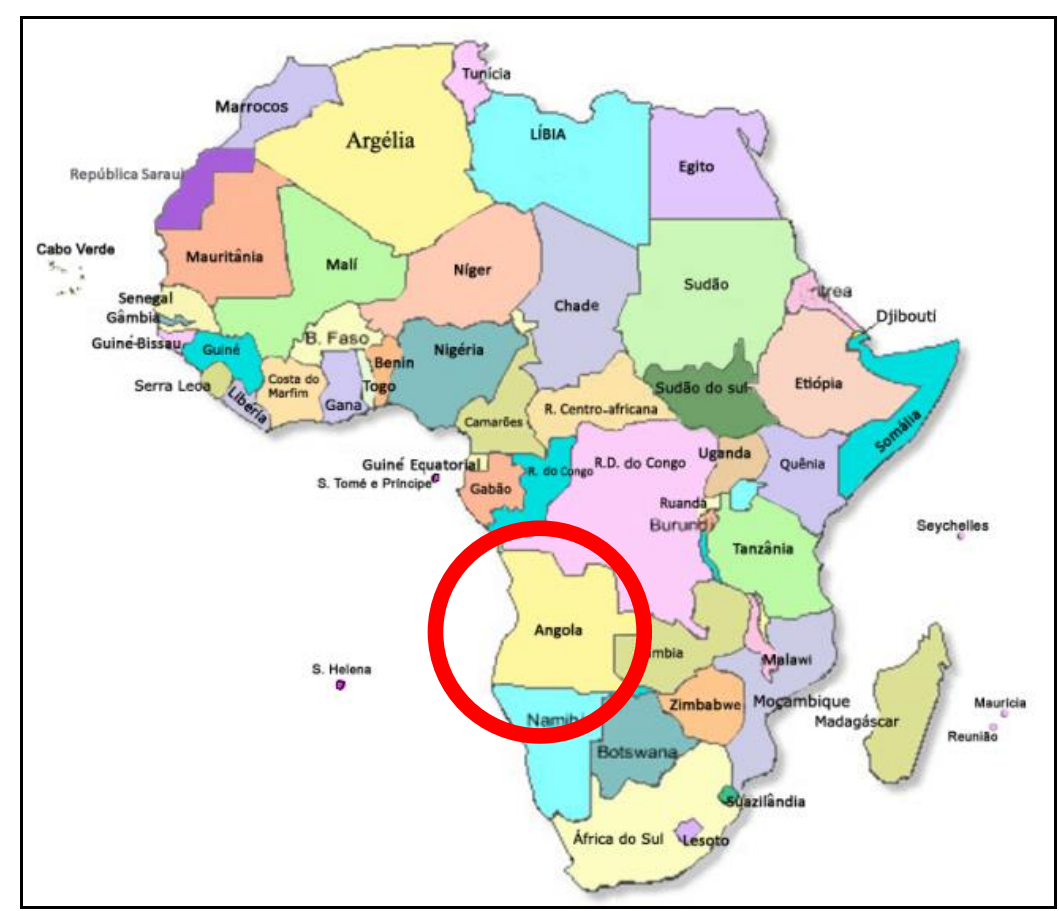

Fonte: Misoafricapt

Interfaces da Educ., Paranaíba, v.11, n.32, p. 606 - 631, 2020 
Mapa 02: Mapa de Angola com destaque à província do Namibe

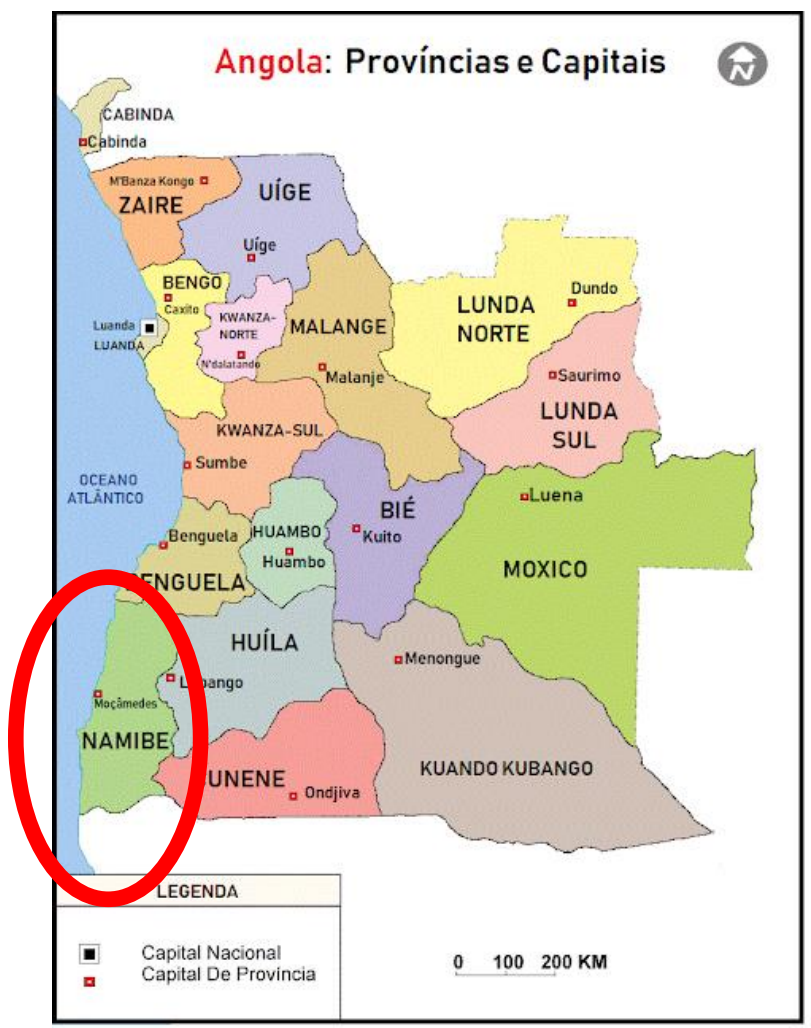

Fonte: Suburbano Digital
Mapa 03: Mapa da província do

Namibe destacando os municípios

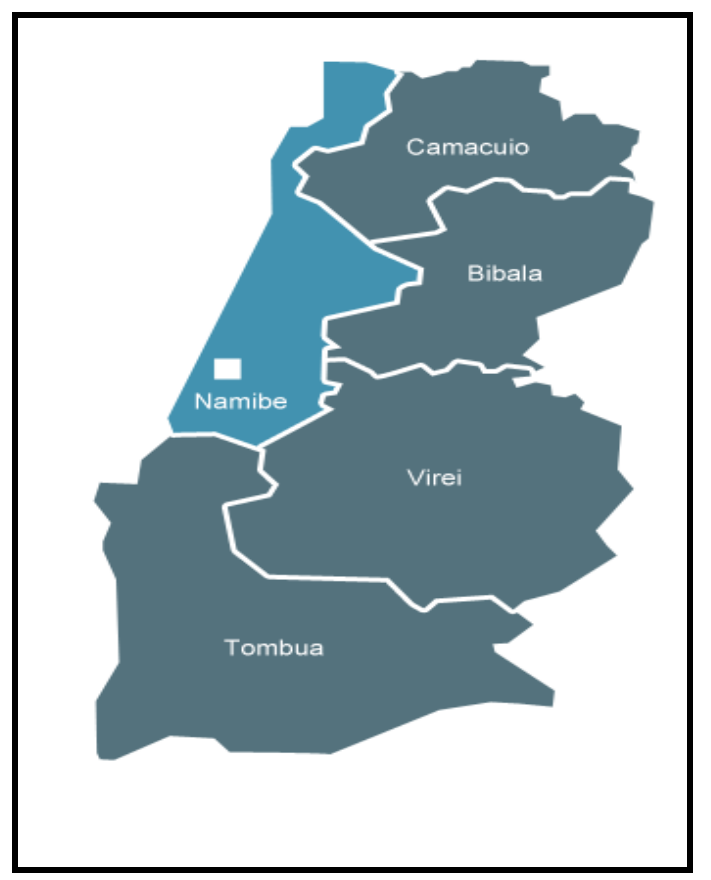

Fonte: FAS

Em primeiro lugar, vale destacar que a província do Namibe é a terceira menos populosa de Angola. Assim sendo, de acordo com os resultados do censo realizado em 2014, vivem no Namibe cerca de 495.327 habitantes, dos quais 64\% vivem na área urbana, e 36\% vivem na área rural - dados do Instituto Nacional de Estatística de Angola ${ }^{2}$ (INE, 2016).

O Namibe constitui-se como uma província maioritariamente desértica. Nesse sentido, o fenômeno da desertificação, que assola principalmente os municípios do Tômbwa, Virei e Camucuio, causa vários prejuizos como fome, morte de gado, improdutividade nas atividades agrícolas, entre outros. Em consequência disso, os diversos povos que habitam no deserto do Namibe, com particular destaque aos mukubais,

2 Dados do Censo de 2014 publicados em setembro de 2016 com o título de Resultados definitivos do Recenseamento geral da população e habitação, 2014, Provincia do Namibe.

Interfaces da Educ., Paranaíba, v.11, n.32, p. 606 - 631, 2020 
dada a necessidade de alimentar o gado, migram para outros lugares a procura de pasto e de água.

Assim sendo, dentre os vários grupos étnicos existentes no Namibe, destacamos o povo Cuvale (Mukubal), uma vez que se trata do povo mais numeroso da província, bem como o mais representativo e marcante. Os habitantes desse grupo estão localizados, sobretudo, na região desértica, no municipio do Virei, bem como na região do rio Curoca.

\section{Referencial teórico}

Em Angola, além do português, são faladas várias outras línguas, que são conhecidas como línguas nacionais. Dessas, as mais faladas são: o Umbundu (22\%), o Kikongo (8\%), o Kimbundu (7\%), o Cokwe (6\%), o Nhaneka (3\%), o Ngangela (3\%), o Fiote $(2 \%)$, o Kwanhama (2\%), Muhumbi (2\%), Luvale (1\%) e outras línguas que representam (3\%), segundo dados do Instituto Nacional de Estatísticas de Angola (INE, 2014). Assim sendo, com $71 \%$ de falantes, o português é a língua mais falada e a única língua oficial de Angola, isso de acordo com dados do último Censo Geral da População e da Habitação realizado em 2014.

Em função desse panorama, a situação linguística do Namibe reflete em muito o cenário nacional, cujas principais línguas são as seguintes: Português $67,9 \%$, Umbundu 20,2\%, Nyaneka 11,9\%, Muhumbi 11,2\%, Luvale 2,4\%, Nganguela 1,2\%, Kimbundu 0,9\%, Kikongo 0,8\%, Fiote 0,6\%, Kwanhama 0,5\%, Côkwe 0,5\%, e as outras línguas faladas correspondem a $7,1 \%$, de acordo com dados do Instituto Nacional de Estatística de Angola (INE, 2016, p.38), como podemos constatar a partir do gráfico 01 e do mapa 04: 
Gráfico 01: Línguas mais faladas no Namibe, 2014

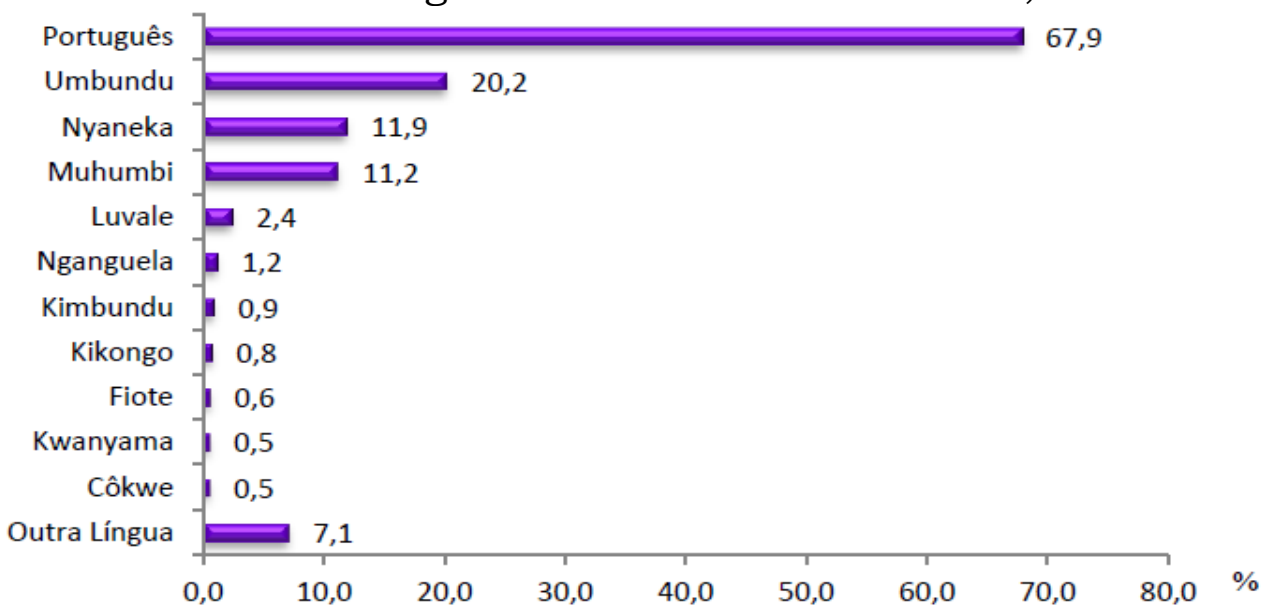

Fonte: INE, 2016, p.38.

Mapa 04: Línguas mais faladas por município

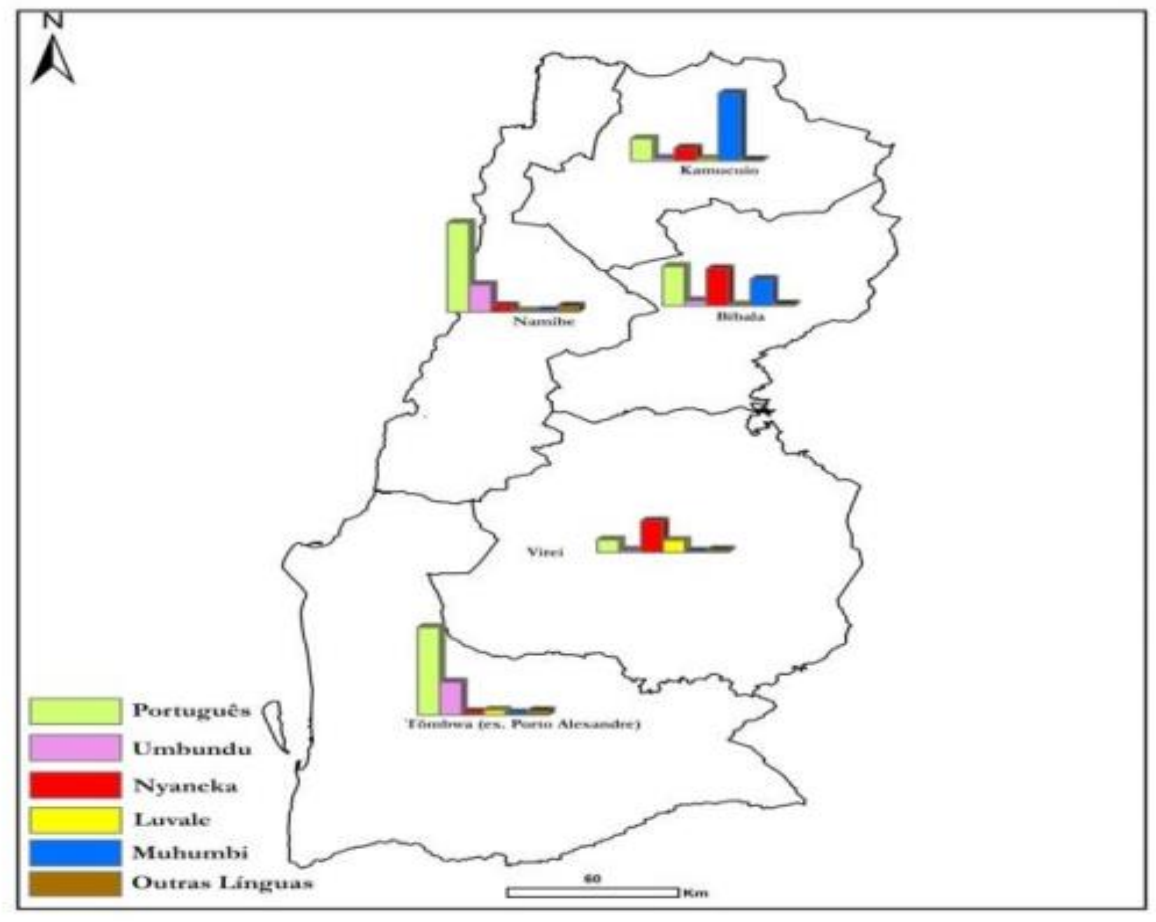

Fonte: INE, 2016, p.38.

Sendo a única língua oficial do país, o português é usado nas instituições públicas e privadas e é a língua de ensino nas escolas angolanas. O contacto dessas línguas nacionais com o português leva os falantes angolanos ao uso de uma variedade de português diferente da variedade europeia. Essa variedade angolana da língua portuguesa não é Interfaces da Educ., Paranaíba, v.11, n.32, p. 606 - 631, 2020 
respeitada, tampouco aceita em várias instâncias da sociedade, principalmente na área educacional, uma vez que se insiste em ensinar a norma lusitana, baseada em tradicionais gramáticas normativas europeias nas escolas angolanas.

Sabendo que Angola possui uma variedade do português que difere do português europeu, advogamos no sentido de que as questões de ensino, sobretudo as de lingua, devem atender à realidade sociocultural de Angola. Sobre esta questão Bernardo (2017, p.48) considera que "o ensino da língua em Angola baseado no normativismo, fixado à gramática tradicional do PE, não espelha a realidade linguística angolana.”. Desse modo, em função de um uma política de Estado, os professores promovem o preconceito linguístico, porque não admitem as variedades linguísticas nacionais, dificultando assim o processo de ensino e aprendizagem. Isso tem influenciado negativamente no desempenho dos alunos nas suas atividades acadêmicas. Com isso, é necessário que reconheçamos a variedade angolana da língua portuguesa como legítima, para que os alunos aprendam aspectos da sua língua e que se revejam na língua em que falam, ou seja, que não sejam conduzidos a uma variedade que esteja longe de suas vivências e da realidade sociocultural, tal como apela Bernardo (2017):

É necessário que haja um reconhecimento da diversidade linguística inerente à sociedade angolana, de modo que as realidades de variação linguística sejam observadas, pois a norma "qualquer que seja, não pode ser compreendida apenas como um conjunto de formas linguísticas [variantes]; ela é também (e principalmente) um agregado de valores socioculturais articulados". (Bernardo, 2017, p. 43).

É evidente que, apesar de o português ser uma língua ex-colonial, imposta através do processo de colonização, para o caso de Angola e para outros países africanos de língua oficial portuguesa, a adoção do português como lingua oficial foi por uma questão estratégica. Sobre esse assunto, Balsalobre (2017, p.46) afirma que "a adoção da lingua portuguesa pelos países africanos contribuiu para que esse idioma se inserisse no mercado linguístico global como um dos mais importantes e representativos". Desse Interfaces da Educ., Paranaíba, v.11, n.32, p. 606 - 631, 2020 
modo, com a configuração de nação autônoma - para o caso de Angola a partir de 1975, ano em que se tornou independente -, a língua portuguesa ganhou outro estatuto e valor, na medida em que boa parte dos angolanos passaram a utilizar e a ter uma identificação e ligação muito forte com o português. Trata-se de um idioma diferente se comparado com o europeu, resultados dos fatores culturais, sociais e geográficos, que podemos chamar de português angolano. Em conformidade com o que atesta Firmino (2006):

As línguas ex-coloniais não permaneceram como produtos estáticos, mas adquiriram novos significados simbólicos e aspectos estruturais, elevando-se ao estatuto de variantes linguísticas com valor próprio e não exclusivamente como meras distorções folclóricas das línguas europeias. Como aponta Tengan (1994), as sociedades africanas nunca foram sistemas fechados, imunes a uma integração de novos elementos e a transformações ou mudanças devidas a influências externas. Pelo contrário, elas têm estruturas abertas que admitem, num processo contínuo, a entrada de novas realidades e de elementos a serem transformados e adaptados ao contexto africano. As transformações das línguas europeias em África são parte deste processo, em que elas se acomodam às realidades socioculturais e políticas em mudança acelerada". (FIRMINO, 2006, p.46).

Dessa forma, comprova-se o pressuposto fundamental da Sociolinguística, ou seja, a língua não é um fenômeno homogêneo, que pode ser analisado de uma única forma, pois há fenômenos variáveis que interferem na realização linguística, tais como a realidade socioeconômica, a região do falante, idade, gênero, etnia, entre outros. Assim sendo, no contexto de sala de aula, é importante que o professor identifique esses elementos múltiplos variáveis e que fortaleça a autoestima do aluno, sobretudo quando perceber que se trata de um estudante proveniente de lugares desfavorecidos socioeconomicamente e estigmatizados, de modo que ele não se sinta excluído do seu meio social. Inclusive, essa tem sido uma das propostas da Sociolinguística Educacional, como realça Cyranka (2006):

A Sociolinguística Educacional propõe que se leve para as salas de aula a discussão sobre a variação linguística, orientando os alunos a reconhecerem as diferenças dialetais e, mais importante, a compreenderem que essas diferenças são normais, legitimas e que devem ser consideradas na seleção das estruturas a serem utilizadas, a depender das condições de produção, isto é, das necessidades do leitor/ escritor, falante /interlocutor, a partir do contexto em que se encontra. (CYRANKA, 2006, p. 169).

Interfaces da Educ., Paranaíba, v.11, n.32, p. 606 - 631, 2020 
Com a finalidade de se preparar o aluno para lidar com as diferenças linguísticas em sala de aula sem estigmatizá-lo, Cyranka (2016, p. 172) faz a seguinte recomendação: "De qualquer modo, é recomendável que a reflexão sociolinguística faça parte da vida escolar desde os primeiros anos, para que se vá construindo uma concepção de linguagem que a compreenda como forma de interação". Portanto, a Sociolinguística Educacional propõe ao ensino de língua portuguesa outra concepção de linguagem - diferente da proposta normativa - e um campo que traz recursos para o bom funcionamento do processo de ensino-aprendizagem, não só para os professores de língua portuguesa, assim como de outras disciplinas.

Nessa linha de raciocínio, entendemos que seria oportuno se a escola valorizasse as variedades que socialmente são estigmatizadas, compreendendo que elas são linguisticamente iguais as outras e, por isso, podem certamente servir de código de comunicação em função da adaptação ao contexto social. É possivel ensinar a norma culta, portanto, sem reprovar as variedades que os alunos de camadas populares trazem consigo. Assim sendo, a escola estaria a recuperar a autoestima desse aluno, respeitando sua cultura e sua comunidade linguística. Para esse efeito, Zilles e Faraco (2015) propõem

\footnotetext{
que os professores desenvolvam uma pedagogia da variação linguística, a partir do reconhecimento de que não existem erros nos usos que os falantes fazem de sua lingua materna, sendo necessário desconstruir modos de pensar equivocados, principalmente no trabalho escolar com a linguagem. (ZILLES; FARACO, 2015, p. 33).
}

No panorama brasileiro da Sociolinguística Educacional, merece destaque a pesquisadora Stella Maris Bortoni-Ricardo, que milita no sentido de propor uma "pedagogia culturalmente sensivel". Trata-se de um termo postulado por Frederick Erickson (1987), que se caracteriza como "um tipo de esforço especial empreendido pela escola, a fim de reduzir os problemas de comunicação entre professores e alunos, de desenvolver confiança e 
impedir a gênese de conflito que se move rapidamente para além das dificuldades de comunicação" (p.118). Assim sendo, é objetivo da pedagogia culturalmente sensivel criar em sala de aula ambientes de aprendizagem onde se desenvolvem padrões de participação social, modos de falar e rotinas comunicativas presentes na cultura dos alunos. Tal ajustamento nos processos interacionais é facilitador da transmissão do conhecimento, na medida em que se ativam nos educandos processos cognitivos associados aos processos sociais que lhes são familiares. Assim sendo, "a pesquisa tem mostrado que professores sensíveis às diferenças sociolinguísticas e culturais desenvolvem intuitivamente estratégias interacionais em sala de aula que são altamente positivas". (BORTONI-RICARDO, 2005, p.128).

Como subsídio a essa discussão do ensino de língua portuguesa, é fundamental salientar o papel da norma linguística. Segundo Faraco (2008), por norma linguística é possivel entender aquilo que é normal, corriqueiro, habitual em dada comunidade de fala. Contudo, a norma padrão é conhecida como aquela que define regras para determinar o certo e o errado, descritas nas gramáticas. Geralmente, não é usada nas interações pessoais no dia-a-dia e é resultado do ensino nas escolas. Essa variedade tem um caráter abstrato, porque ninguém fala de forma tal qual a gramática tradicional orienta. Ela não é, pois, natural. Historicamente, por ser resultado da cultura letrada, passou a ser a única variedade reconhecida pelas instituições governamentais, mantendo-se acima de todas as outras, ocultando assim as outras existentes, e passando a ideia de que a lingua é única entre os povos, como reforçam Cyranka e Pernambuco (2008):

\footnotetext{
O prestígio da variedade padrão, leia-se da escrita, a faz exercer certo poder unificador das outras variedades sem, no entanto, conseguir frear o caráter naturalmente heterogêneo característico de qualquer língua, nem mesmo chegando a impedir que recaiam sobre ela mesma as influências das outras normas sociais. (CYRANKA; PERNAMBUCO, 2008, p.19).
}

De acordo com Bagno (2012, p. 40-41), coadunando com a perspectiva de Faraco (2008), os teóricos consideram que o termo norma pode ser Interfaces da Educ., Paranaíba, v.11, n.32, p. 606 - 631, 2020 
entendido de duas formas: normal e normativo. Assim sendo, normal é relativo ao uso corrente, real e frequente da língua. Entretanto, normativo é referente aos preceitos e ideais a serem seguidos. Nesse sentido, a norma culta é caracterizada como sendo aquela que é usada correntemente por um determinado grupo social privilegiado, com alto nível de escolaridade, tal como define Bagno (2012):

[...] A outra definição que se dá ao rótulo de norma culta se refere à linguagem concretamente empregada pelos cidadãos que pertencem aos seguimentos mais favorecidos da nossa população. Esta é a noção de norma culta que vem sendo empregada em diversos empreendimentos científicos como, por exemplo o projeto NURC (Norma Urbana Culta), que desde o início dos anos 1970 vem documentando e analisando a linguagem efetivamente usada pelos falantes cultos de cinco grandes cidades brasileiras (Recife, Salvador, Rio de Janeiro, São Paulo e Porto Alegre), sendo estes falantes cultos definidos por dois critérios de base de escolaridade superior completa e antecedentes biográfico-culturais urbanos. (BAGNO, 2012, p. 51).

Por sua vez, Cyranka e Pernanbuco (2008, p. 18) definem norma culta como sendo aquela que é resultado de práticas sociais de determinados grupos com nível acadêmico elevado, que dominam a fala e a escrita formal, habitantes dos centros urbanos. Entretanto, Bagno (2009, p.65) sugere que essa norma seja chamada de variedade de prestígio ou ainda variedades prestigiadas, pois, em outras palavras, ele considera que a questão da língua não é de todo o problema, mas sim o prestígio social do falante.

Por fim, convém debruçar-nos sobre normas populares. De acordo com Bagno (2009, p.67), os grupos sociais dominantes, as classes privilegiadas, que constituem a elite de uma sociedade, caracterizam as normas populares como sendo incultas, erradas, desprestigiadas e extremamente negativas, classificando, assim, a fala dos grupos sociais desprestigiados, subalternos e oprimidos. Assim sendo, com a finalidade de não reproduzirmos preconceitos com esses grupos, Bagno (2009) sugere que chamemos de variedades estigmatizadas, e não norma popular, que carrega um sentido pejorativo. É importante evidenciar que nenhuma variedade linguística é superior a outra no que se refere ao seu aspecto gramatical, ou seja, todas as variedades têm a mesma importância linguística. Nesse sentido, cada Interfaces da Educ., Paranaíba, v.11, n.32, p. 606 - 631, 2020 
falante pode usar a variedade em que fala para livremente exprimir os seus pensamentos e interagir com os demais membros de sua comunidade.

\section{Metodologia}

$\mathrm{Na}$ fase inicial dessa pesquisa, os primeiros passos do percurso metodológico tiveram como foco leituras de textos teóricos. Desse modo, feznecessário compreendermos a situação da educação em Angola, de modo geral, e da Província do Namibe, de forma particular. Além disso, também foi importante compreender o ponto de vista dos principais autores que se dedicam à Sociolinguística Educacional e à Pedagogia culturalmente sensivel, e, de uma forma mais detida, entender os conceitos de norma culta, norma padrão e norma popular (variedades estigmatizadas).

$\mathrm{Na}$ fase subsequente, analisamos os livros didáticos de Língua Portuguesa da $7^{\mathrm{a}}$ a $12^{\mathrm{a}}$ classe utilizados em Angola. Com esse intento, debruçamo-nos em temas como a presença ou ausência de discussão sobre a variação linguística; o tratamento dado ao texto literário; a questão do gênero e da tipologia textual; a metalinguagem; a presença de línguas nacionais nos textos; o conceito de língua; e nos empenhamos em estabelecer uma análise geral dos textos escolhidos pelos autores.

Após a análise dos livros didáticos, demos continuidade a esse trabalho científico dedicando-nos à realização de entrevistas. Para tal fim, elaboramos previamente um questionário contendo oito perguntas a serem feitas a estudantes da Provincia do Namibe, em Angola. Para essa pesquisa, foram entrevistadas 13 pessoas com o auxílio de um colaborador local ${ }^{3}$. Ele ficou como responsável pela realização das entrevistas com os alunos namibenses que já terminaram o ensino médio. Feitas as entrevistas, ele nos enviou os áudios com as respostas dos participantes e o termo de consentimento livre

\footnotetext{
3 Aproveitamos o ensejo para expressarmos nossa gratidão ao Professor Albano, sem o qual esse trabalho científico não teria sido possivel.

Interfaces da Educ., Paranaíba, v.11, n.32, p. 606 - 631, 2020
} 
e esclarecido assinado e datado por cada colaborador, para em seguida serem feitas as análises.

Relativamente às línguas nacionais, cinco dos entrevistados têm o umbundu como segunda língua. De Nhaneca umbi há um falante, de Nganguela igualmente um falante e os outros quatro não falam nenhuma língua nacional ${ }^{4}$. É importante salientar que os dados linguísticos dos entrevistados são condizentes com o mapa linguístico divulgado pelo INE (Instituto Nacional de Estatísticas de Angola), em 2016, na medida em que os entrevistados da presente pesquisa, de modo geral, são falantes de língua portuguesa e apresentam o umbundu como a segunda língua mais falada. Por fim, convém salientar que todos os participantes da entrevista fizeram o ensino médio na Escola de Formação de Professores e do Magistério Primário Patrice Lumunba, situada no município de Moçâmedes, província do Namibe. A grande maioria dos participantes terminou recentemente o ensino médio, e durante os anos de escolaridade, foi possivel perceber um equilíbrio entre os que tiveram acesso a livro didático e os que não tiveram.

\section{Discussão dos dados: livros didáticos e entrevistas com estudantes}

De modo geral, os estudantes da Província do Namibe, em Angola, utilizam os mesmos livros didáticos que circulam pelo país todo. Nesse sentido, não se observam especificidades no ensino dedicado aos estudantes namibenses. Em função disso, a partir de agora, seguem reflexões condizentes aos livros didáticos de lingua portuguesa a que os estudantes

\footnotetext{
${ }^{4}$ A respeito dos entrevistados, vale salientar que cada angolano pertence a um grupo étnicolinguístico, embora nem todos falem fluentemente a lingua do grupo a que pertence. Assim, o domínio dessas línguas étnicas varia em função de diferentes fatores, tais como: 1) residência em áreas urbanas, onde há poucos contextos frequentes de uso; 2) uso da língua no seio familiar; 3) número de integrantes do mesmo grupo existente ao redor; etc. Contudo, ainda que alguns entrevistados tenham afirmado que não falem fluentemente uma língua étnica, muito possivelmente, a compreendem de forma razoável.
}

Interfaces da Educ., Paranaíba, v.11, n.32, p. 606 - 631, 2020 
têm acesso e geradas a partir das respostas dadas pelos entrevistados em função do questionário a que foram submetidos.

Os livros didáticos de Língua Portuguesa da $7^{\mathrm{a}}, 8^{\mathrm{a}}$ e $9^{\mathrm{a}}$ classe não são tão diferentes em termos de organização e propostas de conteúdo. Estão praticamente organizados do mesmo jeito, ou seja, a partir da noção de tipologias textuais. Nesse sentido, em cada classe, há o acréscimo de uma tipologia textual. Assim sendo, além de textos narrativos, descritivos, poéticos, informativos, injuntivos/apelativos que estão presentes no livro da $7^{\text {a }}$ classe, no da $8^{\text {a }}$ classe acrescentou-se uma tipologia, a saber: textos explicativos. Por sua vez, na $9^{\text {a }}$ classe foram acrescentados textos argumentativos. Além disso, todos os livros apresentam um bloco gramatical no final para consulta e dúvidas na resolução dos exercícios.

No livro da $8^{a}$ classe, há uma seção inicial denominada "Caro leitor e caro professor". Nessa seção, o livro didático propõe que os alunos aprendam assuntos relacionados à cultura, à literatura, à moral e a aspectos sociais de Angola. Nesse sentido, os autores da $8^{a}$ classe apresentam o livro aos alunos como sendo o "fiel companheiro", na medida em que ele proporcionará um "verdadeiro crescimento integral". É possível destacar que, para o crescimento integral dos alunos, os autores apresentam as seguintes propostas de atividades: “... podes recorrer a várias técnicas, como pesquisa, a investigação, o debate e a troca de impressões com os colegas da tua turma ou de outras turmas ou escolas" (ALMEIDA; PEDRO, 2003, p.4). Em função dos elementos destacados, possibilitam os alunos a terem contacto com as tipologias textuais e suas características específicas, bem como trabalhar os variados gêneros textuais.

Sabe-se que o livro didático é um dos materiais importantes para auxiliar o aluno em suas atividades escolares. Assim sendo, é de suma importância que os alunos tenham acesso a esse material, tendo em vista que ele é tido como o "fiel companheiro". Assim, principalmente para a disciplina de Língua Portuguesa - associada à Matemática, as quais detêm a maior carga horária na grade curricular de ensino em Angola - entendemos Interfaces da Educ., Paranaíba, v.11, n.32, p. 606 - 631, 2020 
que o livro didático oferece oportuna contribuição. Dessa forma, para que os alunos desenvolvam atividades de português dentro e fora da escola, como previsto na carta dos autores dirigida aos alunos, é necessário que todos tenham acesso aos livros. Porém, esse fiel companheiro, em muitos casos, não fez parte dos materiais didáticos de muitos namibenses, tal como podemos constatar nos relatos que estudantes nos fizeram durante as entrevistas realizadas para este trabalho.

É válido destacar que o ensino médio de Angola é composto pelas seguintes séries: $10^{\mathrm{a}}, 11^{\mathrm{a}}, 12^{\mathrm{a}}$ e $13^{\mathrm{a}}$ classe (essa última é dedicada aos alunos interessados em cursarem o magistério). Nesse sentido, para cada classe, existe um livro didático de Língua Portuguesa, exceto a $13^{a}$ classe. Tal como os livros didáticos do ensino base, os livros didáticos do ensino médio também estão organizados por tipologias textuais. Em função disso, no início de cada unidade há uma tipologia a ser estudada e os autores apresentam um bloco explicativo sobre essa tipologia.

Além disso, para resolver os assuntos do funcionamento da língua, no final do livro, podemos encontrar um bloco gramatical para consulta, que funcionam como uma espécie de "gramática". Nesse sentido, acreditamos que o uso desses blocos não é de todo negativo, porém há que ter um equilíbrio do seu uso, e não o colocar como o elemento indispensável para as aulas de Língua Portuguesa, ou seja, como se a aula de português se resumisse simplesmente em gramática. Desse modo, promove-se uma segregação, sobretudo para os alunos que provêm de uma realidade socialmente não privilegiada.

Assim sendo, à luz da Sociolinguística Educacional, entendemos que é possivel desenvolver práticas de ensino de língua, sobretudo com alunos provenientes de classes sociais desfavorecidas (e que não dominam a norma culta do português), ou cuja língua materna não seja o português, de modo a fazer com que se sintam acolhidos e incluídos. A partir dessa perspectiva de Interfaces da Educ., Paranaíba, v.11, n.32, p. 606 - 631, 2020 
ensino e de aprendizagem, entendemos que todos os alunos possam ser ensinados a utilizar outras normas linguísticas de modo a participar satisfatoriamente das práticas sociais que exigem conhecimentos linguísticos variados.

Nesses livros didáticos do ensino médio, além das tipologias textuais existentes, também podemos encontrar vários gêneros textuais, com maior destaque aos textos literários de autores angolanos para serem trabalhados em sala de aula e fora da escola. Acerca disso, os autores destacam: "De facto, se consideramos os grandes autores como os melhores mestres, são também eles os modelos a quem recorremos na nossa avidez pelo saber, pelo saber fazer" (AIROSA, 2015, p.03). Como observado por meio desse excerto, compreendem-se os grandes autores angolanos como modelo e referência para o ensino de Língua Portuguesa através dos seus textos.

Como anteriormente expresso, a língua de ensino de Angola é o português. Isso está na Constituição Nacional e na Lei de Base da Educação. No entanto, a norma usada como referência para o processo de ensino e de aprendizagem não é baseada na variedade angolana da língua portuguesa, na medida em que os blocos gramaticais oferecem noções de sintaxe baseadas na lógica do português europeu. Contudo, nos livros didáticos do ensino médio, onde os textos literários são dos "grandes autores nacionais", encontramos variedades do português angolano. Portanto, constatamos uma contradição fundamental nos livros didáticos em análise: se os "grandes autores" são tidos como "os melhores mestres", por que não são tidas em conta as diferentes variedades do português angolano como legítimas ao processo de escolarização? Justamente, quando essas variações estão presentes nos textos de literatura, não há uma clara intenção de serem estudadas linguisticamente. Ou seja, aparecem nos contos, em narrativas que geralmente retratam a vida de um determinado grupo, mas nas atividades de interpretação de texto, não há qualquer comentário a esse respeito. Assim, vejamos um trecho de um texto literário retirado do livro da $11^{\text {a }}$ classe, na página 187 :

Interfaces da Educ., Paranaíba, v.11, n.32, p. 606 - 631, 2020 


\begin{abstract}
"Um comba, sem tirar nem pôr. Bem geladinhas, lá prás três da manhã, vão-lhes chamar champanhe e se soubesse para cima de vinte seis até me chamavam santo. Quem entrará com tanto combú nesse comba? Ninguém nem o tuga camionista."

"Já não digo nada."

"Mas digo eu. Andamos a enganar-nos a nós próprio e a enganar-nos uns aos outros. É isto a nossa vida. Pois com essa grade ninguém vai enganar mais ninguém! Eu que te digo." (AIROSA, 2015, p.187).
\end{abstract}

Diante do exposto, acreditamos que a Sociolinguística, enquanto elemento de valorização da autoestima do aluno, propõe-se a ampliar a competência linguística do aluno, respeitando a sua cultura, a sua origem e o seu nivel socioeconômico. Assim, leva-o a compreender a diversidade linguística existente, tendo confiança para socializar-se com os demais colegas e em outras instâncias da sociedade.

Conforme destacado previamente, a lingua mais comum no Namibe é o umbundu, após o português. No município do Virei, em função da presença dos mukubais, a língua nyaneka é a mais falada (cf. novamente o mapa linguístico da província). A partir desse panorama, o município do Virei, assim como em outras comunidades onde o português não é a língua mais falada, o português continua sendo a língua de ensino, muito embora essa situação cause muitas dificuldades para o processo mais amplo de escolarização. Nesse sentido, advogamos que o Estado, responsável pela educação, deveria adotar medidas para que realidades como a do Virei pudessem ter suas linguas locais implementadas como linguas de ensino.

Sabe-se que, sempre que há duas ou mais linguas dentro de uma comunidade, há possibilidades de que uma venha a influenciar a outra, ou mesmo as duas terem influência uma da outra. Nesse sentido, constatamos que esse fenômeno acontece no Namibe, pois temos relatos de que, em algumas situações, o falante usa regras de uma língua inconscientemente para usar em outra. Esse é o caso de um dos nossos entrevistados, falante de português como primeira língua e de umbundu como segunda língua. A esse entrevistado, quando feita a sexta questão ("Como estudante na província do Namibe, você acredita que o ensino de língua portuguesa 
corresponde ao jeito como vocês falam normalmente? Por quê? Justifique sua resposta"), ele faz a seguinte reflexão:

\begin{abstract}
...Primeiro é mesmo a tal colocação dos pronomes que nós nos desviamos, e segundo é mesmo as interferências linguísticas, pois que... pelo menos no meu caso falo umbundu, e quando falo português noto uma certa influência da minha lingua...da minha língua.... língua segunda nesse caso que é o umbundu sobre o português, tenho tendência de por vezes levar as regras gramaticais do umbundu para português. Por exemplo: quando vou a uma loja pergunto hum... no português o correcto seria: quanto é o pão? Mas eu pergunto o pão é quanto, isso é uma regra específica do umbundu e eu levo para o português, aí está também a interferência. $(\text { Entrevistado A })^{5}$
\end{abstract}

Adicionalmente, arguindo a partir da mesma ideia, ao ser submetido também à sexta questão, obtivemos o relato de outro entrevistado, que tem o português como língua primeira e como língua segunda tem a língua nganguela, que é uma das línguas faladas no Namibe. Para ele:

Os estudantes do Namibe passam mais tempo em casa ou na rua e lá aprendem alguns vocabulários que não têm correspondência linguística ou não estão dentro do português padrão, face a essa situação a dificuldade naquilo que será a aprendizagem porque o estudante vai se habituar com uma outra expressão. Exemplo da frase que muitos falam na rua: te amo, não seria assim, que é amote. Porque há uma interferência no português local. (Entrevistado E)

Para os dois casos relatados, constatamos a falta de reflexão sobre a existência da variação linguística, ou seja, há uma cobrança para que os alunos falem tal qual as regras que constam nas gramáticas, sendo que ninguém fala tal como orienta a norma padrão que rege os compêndios gramaticais. Assim, essa impressão sobre não se falar conforme as regras da gramática causa nos alunos o sentimento de que não sabem falar o português ou falam erradamente. Nesse sentido, quando se ensina a Língua Portuguesa, deve-se ter em conta a abordagem da variação linguística. Desse modo, o professor, tendo consciência da diversidade linguística, conhecendo a realidade linguística de sua turma, poderá ensinar não apenas a norma culta, como apresentar outras possibilidades legitimas, como a norma popular, e diferenciar os contextos em que cada uma é utilizada. Por sua

\footnotetext{
${ }^{5}$ Em função de nossa responsabilidade ética, a identidade dos entrevistados foi suprimida. Interfaces da Educ., Paranaíba, v.11, n.32, p. 606 - 631, 2020
} 
vez, essa é a orientação da Sociolinguística Educacional: que a escola ajude os alunos a desenvolverem suas competências comunicativas na modalidade falada e escrita. (CYRANKA, 2015, p. 32).

É importante salientar que os livros didáticos angolanos são feitos para serem distribuídos para o país todo. Contudo, as linguas nacionais presentes nos textos não abrangem todas as linguas nacionais faladas no Namibe. Ou seja, em exemplos pontuais que podem ser encontrados ao longo de textos, privilegiam-se as línguas mais faladas em Angola, como é o caso do umbundu, do kimbundu e do kikongo, deixando sem representatividade várias línguas faladas no Namibe.

Ademais, destaca-se o fato de que os exemplos pontuais das línguas nacionais que estão representadas nos livros didáticos surgem sem a clara intenção de serem estudadas. Assim sendo, essas palavras ou expressões geralmente aparecem quando o texto retrata uma situação típica de áreas rurais - como recurso dado à liberdade artística do autor -, ou ainda para nomear pessoas, lugares, rituais e objetos que não têm significado correspondente para o português. Assim sendo, podemos constatar no manual da $7^{a}$ classe, nas páginas 14 e 15, uma fábula angolana na qual há palavras em língua nacional umbundu e kimbundu. Nesse texto, por exemplo, fala-se em "jango" (tribunal tradicional) e em "kimbo" (aldeia, pequena comunidade rural), mas não se aproveita a oportunidade para discutir questões jurídicas importantes para a realidade angolana, tampouco estimula-se reflexões sobre variação lexical.

Vale salientar que a língua não é homogênea e que as comunidades também não são. Desse modo, em Angola, as regiões possuem particularidades relativamente à fala, o que podemos compreender como variedades do português de Angola. No entanto, os livros didáticos apresentam pouca orientação teórica sobre variação linguística e, ainda assim, de uma forma pouco adequada. Assim, no livro da $8^{a}$ classe, na página 198, há uma parte teórica sobre "registro de língua", entretanto, não 
há qualquer aplicação prática acerca desse conteúdo ao longo desse livro e nos demais.

Vejamos como os autores definem o conceito de regionalismo: "diversidade de linguagem característica de uma região, quer a nível fónico (pela diferente pronúncia de sons), quer a nível lexical (uso de palavras diferentes para o mesmo conceito)" (ALMEIDA; PEDRO, 2008, p.198). Como exemplo de regionalismo, usam as palavras "sertã/frigideira", porém não apresentam em qual região do país usa-se "sertã" e em qual se usa "frigideira", tal como não apresentam exemplos de variação regional em nível fonético e sintático.

É notório que os autores dos livros da $11^{\mathrm{a}}$ e da $12^{\mathrm{a}}$ classe tratam com certo preconceito o "registro popular" ao afirmarem o seguinte: "utilizado pelas camadas da população menos instruídas. Caracteriza-se por uma linguagem muito simples, frequentemente incorreta em termos de sintaxe e pronúncia, deturpando-se frequentemente as palavras". (AIROSA, 2015, p.215 - grifos nossos). Sob o mesmo ponto de vista, retratam o "calão" como sendo: “...caracteriza-se pela utilização de termos considerados grosseiros e rudes". (AIROSA, 2015, p.216 - grifos nossos).

Nesse sentido, com esses conceitos, os autores desses livros entram em contradição, uma vez que - como destacado anteriormente - eles têm os grandes escritores nacionais como modelo e, justamente, esses escritores, em seus textos, usam calão e o registro popular! Esse é o caso, por exemplo, de Manuel Rui, que no seu texto, reproduzido na página 187 no livro da $11^{\text {a }}$ classe, usa a seguinte expressão: "Quem entrará com tanto combú nesse comba?" (AIROSA, 2015, p.187). Nesse caso, "cumbú" é um calão que corresponde a dinheiro. No mesmo texto, encontramos a seguinte frase “...aquela cota viúva que morava lá no fundo...". Para este caso, a palavra "cota" refere-se à "senhora", alguém de maior idade. Essa palavra "cota", popularmente usada pelos angolanos, entretanto, não é vista como errada, uma vez que é usada por todos, desde os escolarizados até os não escolarizados. Em função disso, de tanto preconceito que o calão sofre, Interfaces da Educ., Paranaíba, v.11, n.32, p. 606 - 631, 2020 
generaliza-se, e os livros didáticos tendem a associar o seu usuário a uma pessoa marginal, sem cultura, até mesmo como alguém sem educação. Dessa forma, a partir da fala de um entrevistado, constatamos a visão negativa que se tem do calão, quando se diz o seguinte:

Porque por exemplo hoje temos muitas influências, sobretudo
influências no que diz respeito a calão né, no que diz respeito... as
pessoas falam só porque querem falar, falam simplesmente aquilo
que lhes vier à mente, temos ainda dificuldades de organizar as
palavras certas, pronunciá-las de forma certas também.
(Entrevistado M)

De modo geral, através dos livros didáticos e das entrevistas realizadas, percebemos que o ensino de Lingua Portuguesa em Angola, especificamente na província do Namibe, é pautado na gramática tradicional, ou seja, aos alunos passa-se a ideia de que, para falar o "bom português", precisamos memorizar as regras gramaticais e fazer um monitoramento para verificar se estamos a falar tal como dizem os compêndios gramaticais. Por exemplo, vejamos a fala de um dos entrevistados:

...É... porque, porque a princípio é o meio em que nos encontramos, muita das vezes nós falamos vulgarmente porque as vezes é o meio e também não seguimos as regras gramaticais que nos são ensinados. (Entrevistado $\mathrm{H})$

Por sua vez, outro entrevistado acrescenta o seguinte:

Porque a partir do momento em que começamos a estudar nas classes anteriores os professores nós crescemos assim os professores ensinavam simplesmente gramáticas, muita teoria pouca prática, nós simplesmente escreviamos o que estava no caderno não sabíamos como usar no momento de lazer. (Entrevistado C)

Assim sendo, os alunos têm a compreensão de que estudaram toda a teoria gramatical, contudo não conseguem aplicar esses conhecimentos à fala. Assim, sobre essa situação, de acordo com Cyranka (2015), o professor inicialmente precisa ter a compreensão da linguagem como um meio de libertação, para que deste modo possa ampliar as competências linguísticas que os alunos trazem, reconhecendo-as e aceitando-as. Se os alunos sentem que, mesmo tendo muitas aulas de português, não sabem falar essa língua é porque está a ocorrer uma tentativa de apagar a variedade que eles trazem Interfaces da Educ., Paranaíba, v.11, n.32, p. 606 - 631, 2020 
de suas comunidades. Nesse sentido, a Sociolinguística Educacional propõe que temas de variação linguística sejam pautadas em sala de aula constantemente, para evitar o preconceito linguístico e a falta de autoestima por parte dos que falam uma variedade diferente.

Em virtude dos fatos mencionados, entendemos que há uma grande necessidade de melhorarmos o ensino de Língua Portuguesa nas escolas do Namibe, sobretudo no que se refere a conceitos teóricos de linguística, de sociolinguística, de política linguística e a questões metodológicas. Além disso, apesar de alguns professores já estarem preocupados em refletir sobre o ensino do português, precisa-se de maior abertura para que outros possam aderir à causa - na medida em que uma nova política educacional seja promovida. Assim, seria bom que os livros didáticos de português para alunos provenientes da provincia do Namibe fossem feitos a partir da realidade namibense.

\section{Considerações Finais}

Por meio dessa discussão, foi possível estabelecer um breve esboço sobre a forma como tem sido conduzido o ensino de Língua Portuguesa em Angola, em particular na província do Namibe, através de textos teóricos, análises de livros didáticos e de entrevistas. Assim sendo, consideramos que há uma grande necessidade de estudar, pesquisar, discutir cada vez mais assuntos relacionados ao tema, sobretudo no que se refere ao Estado, por meio do Ministério da Educação, que é o órgão que regula todo o sistema educativo de Angola. Além disso, as universidades, institutos e outras instituições de educação que formam professores precisam debater mais sobre o tema abordado, porque acreditamos que essas instâncias educativas possam contribuir com a transformação no ensino. Assim sendo, se tivermos professores bem formados, com uma visão crítica, principalmente sobre conceitos e modelos de ensino europeu que vigoram em grande medida no 
sistema de ensino nacional, poderemos ultrapassar grandes barreiras no ensino angolano, fundamentalmente na área de ensino de Língua Portuguesa.

Nesse contexto, com a realização desse estudo, foi possivel nos debruçarmos, particularmente, sobre a província do Namibe. De modo particular, os dados do município do Virei despertaram-nos uma grande curiosidade, sobretudo acerca das razões para a pouca adesão à educação formal. Em nosso entender, ainda não há políticas educacionais para reverter esse quadro em que se encontra o município na vertente educacional. Assim, para atingir a compreensão dessa realidade, nós utilizamos a perspectiva crítica defendida pela Sociolinguística Educacional e pela Pedagogia Culturalmente Sensivel.

Sabe-se que, de maneira geral, o ensino de Língua Portuguesa é pautado primordialmente pela gramática. Ou seja, durante as aulas de português, pode-se fazer leitura, compreensão do texto, mas a questão do funcionamento da língua é caracterizada como o principal momento da aula, para o qual dá-se mais atenção e mais tempo. As entrevistas com os alunos apontam que os namibenses não falam tal como se aprende nas escolas. Isso mostra a necessidade que temos de estudar sobre a variedade linguística namibense e sobre interferências que as línguas nacionais apresentam no português falado no Namibe.

Assim, em última análise, compreendemos que os objetivos propostos para este trabalho foram atingidos. Estamos cientes de que o trabalho apresenta aberturas que podem e devem ser preenchidas por meios de futuras pesquisas e por intermédio de outras reflexões sobre o tema.

\section{Referências}

AIROSA, Maria Filomena Jaime. Língua Portuguesa $11^{a}$ Classe. Luanda: Editora das Letra, SA, 2015.

AIROSA, Maria Filomena Jaime. Lingua Portuguesa $12^{a}$ Classe. Luanda: Editora das Letra, SA, 2015.

Interfaces da Educ., Paranaíba, v.11, n.32, p. 606 - 631, 2020 
ALMEIDA, Helena. PEDRO, Gonçalves. Língua Portuguesa: $9^{a}$ Classe. Manual do aluno. Luanda: INIDE, 2006.

ALMEIDA, Helena. PEDRO, Gonçalves. Língua Portuguesa: $7^{a}$ Classe. Manual do aluno. Luanda: INIDE, 2003.

ALMEIDA, Helena. PEDRO, Gonçalves. Língua Portuguesa: $8^{a}$ Classe. Manual do aluno. Luanda: Textos Editores, 2008.

BAGNO, Marcos. A norma oculta: língua \& poder na sociedade brasileira. $2^{\mathrm{a}}$ ed. São Paulo: Parábola, 2003.

Dicionário crítico de sociolinguística. São Paulo: Parábola, 2017.

BERNARDO, Ezequiel Pedro José. Norma e variação linguística: implicações no ensino da língua portuguesa em Angola. In.: Revista Internacional de Lingua Portuguesa. N.32, 2017, p.39-54.

BORTONI-RICARDO, Stella Maris. Nós cheguemos na escola, e agora? Sociolinguística e educação. SP: Parábola, 2005.

CYRANKA, Lucia. Sociolinguística aplicada à educação. In.: MOLLICA, Maria Cecília; JUNIOR, Celso Ferrarezi. (orgs.). Sociolinguística, sociolinguísticas: uma introdução. SP: Contexto, 2016.

Avaliação das variantes: atitudes e crenças em sala de aula. In.: MARTINS, Marco Antonio et al. (orgs.) Ensino de português e sociolinguística. São Paulo: Contexto, 2014.

BARROSO, Therezinha (orgs.). A pedagogia da variação linguística na escola: experiências bem sucedidas. Londrina: EDUEL, 2018.

FARACO, C. A. Norma Culta Brasileira: desatando alguns nós. São Paulo: Parábola Editorial, 2008.

GOVERNO PROVINCIAL DE NAMIBE. Namibe monografia da provincia. Projeto portal do governo, s/d. Disponivel em: http://www.namibe.gov.ao/.

INE. Censo 2014: Resultados Definitivos do Recenseamento geral da população e da habitação de Angola (2014) Provincia do Namibe. Luanda: INE, 2016.

MAPA atualizado da África. Misosoafricapt, 2012. Disponível em https://misosoafricapt.wordpress.com/2012/03/19/mapa-atualizado-daafrica-2012/. Acesso em 05 jul 2019.

MAPA de Angola com provincias e capitais. Blog de geografia, 2018.

Disponivel em https://suburbanodigital.blogspot.com/2018/01/mapa-deangola-com-provincias-e-capitais.html. Acesso em 05 jul 2019.

Interfaces da Educ., Paranaíba, v.11, n.32, p. 606 - 631, 2020 
MAPA do Namibe. Fundo de apoio Social. FAS Disponivel em http:/ / fas.co.ao/mat/fas-namibe/. Acesso em 05 Agosto 2019.

ZILLES, Ana Maria Stahl, FARACO, Carlos Alberto. (orgs.) Pedagogia da variação linguística: língua, diversidade e ensino. São Paulo: Parábola, 2015. 